\title{
The Relationship Between Green Human Resource Management and Environmental Sustainability: A Case Based on State Commercial Bank in Matale District
}

\author{
R.M. Rushya ${ }^{1}$ \& D.M.T.D. Dissanayake ${ }^{2}$ \\ ${ }^{1,2}$ Department of Business Management \\ Faculty of Business Studies \& Finance \\ Wayamba University of Sri Lanka \\ Kuliyapitiya \\ SRI LANKA \\ rushyamahendran77@gmail.com ${ }^{1}$, tanyad@wyb.ac.lk ${ }^{2}$
}

\begin{abstract}
Green Human Resource Management (GHRM) has emerged from the participation of companies in environmental conservation activities and ecological balance maintenance. Today, this subject is considered as an evolving and timely topic in Sri Lankan enterprises. But the public banking industry in Sri Lanka is not used much Green HRM practices when considering with private banking industry. This paper aims to find out the relationship between Green HRM \& Environmental Sustainability in Bank of Ceylon in Matale district. Furthermore, this study aims to identify the Green HRM functions which they follows. This study was conducted by using 40 managerial employees in fourteen Bank of Ceylon branches in Matale district. This research endowed with exploratory study design pattern and quantitative research approach. Data was collected by survey method. When considering the results, Environmental Sustainability has a positive relationship with Green Job design, Green Recruitment \& Selection and Green Training \& Development. But the Green Performance \& Reward Management has a negative relationship with Environmental Sustainability.
\end{abstract}

Keywords -: Green HRM, Environmental Sustainability, Green HRM functions, Public banking sector

\section{INTRODUCTION}

Environmental issues (Climate change, global warming, environment pollution, energy crises, etc.) are becoming more concern around the world today. This situation requires the contribution of all individuals and organizations to tackling issues and challenges in a sustainable way (Arulrajah et al, 2016). Rising seas and increased coastal flooding, more destructive hurricanes, frequent and intense heat waves, widespread forest death, increased health impacts, heavier rainfall and floods, more severe droughts in some regions, increased pressure on ground water supplies, changing seasons, melting ice, food supply disruptions; all are the phenomena of the impact of global climate change. The Great Barrier Reef, Glacier National Park, The Dead Sea, The Amazon, Yamal Peninsula, Maldives, Indonesia are 
the factual example of the climate change effect (Islam et al,2019).

Environmental concerns, ecological balance and environmental protection have become topics for debate across the globe. Organizations as well as consumers have recognized the value of the environment for human survival. Many companies are being used in the present era to operate their business in a green manner and the use of Green HRM is also noteworthy in various organizations. In the twentieth century, Green HRM was the new research area in the organizational analysis.

Green HRM may help to reduce the harmful carbon. That directs the company to use fewer papers and so on. Green HRM is an important technique for making the company and its resources sustainable. Green Human Resources means putting into action and improving employee understanding and confidence at any level of the enterprise on sustainability. Researchers found that various business and non-business organizations took green measures to rebuild their companies and seek to protect the environment from catastrophic effects (Islam et al, 2019).

Green HRM includes environmentally sustainable human resource strategies and activities adopted by companies to accomplish their basic objectives and priorities by reducing the adverse effects of the environment arising from the organization's policies and behavior (Uddin \& Islam, 2015). Environmentally friendly human resources allows public organizations to develop commitment to environmental sustainability by concentrating on green practices such as waste management, recycling, carbon footprint reduction and the use and manufacture of green goods (Ahmad, 2015).

Companies are implementing EMS (Environmental Management System) a strategic tool, to gain competitive advantage. This system provides better control of firm's environmental impacts. It includes commitment, policy, planning, implementation, measurement and evaluation, review and improvement of HR systems that fit with organization's culture and long-term goals. Improved employee morale, stronger public image, increased consumer/customer confidence, employee loyalty and brand recognition, position as an employer of choice, increased workforce productivity, efficiency, motivation and employee retention are few of the many advantages and benefits an organization can have by implementing and developing such Green HRM techniques (Jessy, 2017)

\subsection{Research Problem}

Banks have a very important role to play in nation's economic growth. Encouraging environmentally sound expenditure and lending must be the bank's responsibility. Banks should promote environmentally friendly products, processes and technologies which reduce environmental carbon footprint (Shaumya \& Arulrajah, 2016). Green HRM practices in a bank involves undertaking environment friendly HR initiatives resulting in greater efficiencies, lower 
costs and better employee engagement and retention, which in turn, help organizations to reduce employee carbon footprints by teleconferencing and virtual interviews, recycling, telecommuting, online training, energy-efficient office spaces (Kusumanchi, 2019).

The concept of environmental sustainability has drawn eminently concern regarding corporate stability in the world (Jackling, 2000). After the beginning of the philosophy sustainability, several companies have developed environmental management programmes, policies and techniques to protect the environment (Noronha et al, 2016).However, it is the realization of organizations that, taking care of the environment is beneficial not only to the environment but also to the organizational growth and employee well-being (Likhitkar \& Verma, 2016).They concentrate on integrating human resource management strategies, programmes, processes and environmental protection activities (Haddock-Miller et al, 2016).

Despite gaining position in the literature and its increasing application as a remedy for environmental degradations in many organizations (Sharma, 2016). In many countries and especially in public organizations, Green HRM is still a new phenomenon (Freitas et al, 2012). It is imperative that Sri Lanka understand the concept of green to face the $21^{\text {st }}$ century's most critical yet private challenge, which is the transformation into a sustainable and low- carbon economy (Jayaweera et al, 2012). According to knoema website in 2018, $\mathrm{CO}_{2}$ emissions for Sri Lanka was 23.8 million tones. $\mathrm{CO}_{2}$ emissions of Sri Lanka increased from 9.9 million tons in 1999 to 23.8 million tons in 2018 growing at an average annual rate of $5.14 \%$.

The amount of carbon emissions in Sri Lanka in 2018 was 23.8 million tons. So, considering the effect, this is an immense amount. Since, we are responsible citizens we need to pay attention to this specific problem. Although the emissions in 2018 are lower than in previous years, this is not a small amount. Hence, each of us will continue to take urgent care of our environment.

Even though the concept looks a little new both in Sri Lankan public banking sector and in the entire field of Human Resource Management, BOC has initiated many green HRM practices in recent past (Business Today, 2016). As pe the evidences they have go for digitization in many of the areas. So thy have stared adapting may of the green practices by adapting digitalities ad concerning on environmental sustainability (Annual report, 2015).

Similarly, the paper aims at providing strategies for enhancing environmental sustainability in Sri Lankan public sector banks and further try to identify the Green HRM practices which they are following. Likewise, the study hopes to create more awareness to HR managers and employees about the Green HRM. Green movement and utilization of natural resources also as to help organizations to properly maintain 
and retain the natural environment for future generations.

\subsection{Research Objectives}

This study is mainly aimed to achieve the following objectives,

- To find out the relationship between Green Job Design \& Environmental Sustainability.

- To find out the relationship between Green Recruitment \& Selection and Environmental Sustainability.

- To find out the relationship between Green Training \& Development and Environmental Sustainability.

- To find out the relationship between Green Performance \& Reward Management and Environmental Sustainability.

\subsection{Literature Review}

Milliman and Clair (1996) were among the first to suggest an analysis of the great role of HRM developed a model of surrounding HRM activities involving four key steps in environmental management. First, a company requires an environmental vision as a guideline for shaping its strategy. Second, employees must be trained through their goals and strategy to understand the company's philosophy of environmental vision. Third, environmental performance of workers needs to be measured using a reasonable evaluation framework in accordance with these goals. Four, identifying workplace pro-environmental practices.
Renwick at al. (2013) also outlined three core components of the HR environmental management (EM) aspects. The first core component is related to green skills creation and includes activities such as selecting, recruiting, training and developing environmental knowledge and promoting EM leadership. The second core component is related to the motivation of green employees and implies appraisal and rewards. The third core component is about promoting employee engagement and involves valuing tacit awareness, inspiring workers and building a green organizational culture.

\subsection{Significance of the Study}

Nowadays, there is a growing need for strategic Green HRM; the integration of environmental management into HRM in the perspective of the question of environment pollution in the world. HR professionals can indicate that encouraging employees to be more environmentally friendly in the workplace is the top practice for their organizations.

Business entities have an immense responsibility for the environment as much as people. Since when performing business activities, they create $\mathrm{CO}_{2}$ more than an average individual. Therefore, every organization are accountable to protect the environment. Then, in order to minimize $\mathrm{CO}_{2}$ emissions or preserve the environment a company has to train or make its workers care about it. The Human Resource Management division is the best 
place to do the job and they can convert their ordinary workers into green employees. Work on this subject is very important hence it helps to protect the environment.

Green HRM literature is predominantly western and given the importance of Asian economic growth for environmental management, this is a major gap to minimize in future studies (Renwich et at, 2013). Management scholars around the world are now analyzing various management practices that can facilitate achievements of Green HRM objectives and also have a significant impact on the organization's environmental competitiveness.

In the $21^{\text {st }}$ century, HR professionals will incorporating green signals in conventional HR roles to ensure the climate is healthy and to achieve the organization's competitive edge.

\subsubsection{Environmental Sustainability}

The basic understanding of the term "environmental sustainability "expands our common perception of human activity so as to more clearly connect it with the ecological concept of interdependence, thus delineating the boundaries of this use of "sustainability" to correspond to the overlay of human activity upon the functioning of the supporting eco system. Then Environmental Sustainability is limited to and, in fact, becomes a subset of ecological sustainability. Broadly speaking, the idea of "environmental sustainability" may be seen as adding complexity to a portion of the word "sustainable development" used most widely. i.e.," meeting the needs of the current generation without compromising the ability of future generations to meet their needs, by taking the general definition "meeting the resource and services needs of current and future generations without compromising the health of the ecosystems that provide them.

Specifically, environmental sustainability may be characterized as a state of balance, resilience and interconnectivity that enables human society to meet its needs while not exceeding the capacity of its ecosystems to continue to generate the resources required to meet those needs through our behavior to reduce biological diversity (John, 2011).

\subsubsection{Green Human Resource Management}

\section{What is Green HRM?}

Green Human Resource Management (GHRM) can be defined as the set of policies, practices and systems that stimulate a green behavior of a company's employee in order to create an environmentally sensitive, resource efficient and socially responsible workplace and overall organization (youmatter, 2018).

Green HRM is applied to all activities involved in designing, implementing and sustaining a programme that seeks to green an organization's employees. It is on HRM's side that regular workers are turned into green employees in order to achieve the organization's sustainability objectives and eventually make a meaningful contribution to the environment. It refers to policies, procedures and processes that make 
the organization's workers green for the good of people, society, the environment and industry (Opatha, 2013).

Today the need for Green HRM is important for all over the world. The environmental awareness of each human being drives the living style and environment. The general employees are concerned in green human resource management because of its significance and need in the existing place of work. Our personal and professional lifestyle is affected due to many consequences. The corporate world is the most significant in enhancing the environmental issues and the corporate has to give clarification to this hazard. Nowadays organizations need green HRM for several reasons. Such as, To protect the environmental aspects, to instruct and encourage both financially or non-financially the employees to perform their activities in an environmentally trustworthy way, to increase or improve corporate environmental performance by certain $\mathrm{HR}$ functions such as training employee empowerment and Environmental Management System (EMS) rewards, to motivate employees to become involved in corporate environmental management activities, To provide environmentally friendly products and operations (Masood, 2018).

Green HRM is responsible for building green workforce that recognizes, respects and implements green initiative and retains its green goals in the recruitment, recruiting, training, compensation, growth and advancement of the company's human capital. This refers to the policies, processes and structures that make green organization employees for the good of the individual, community, natural environment and business. Green HRM included two important elements: environmentally sustainable HRM processes and information preservation capital. Green HRM also includes reducing carbon footprint by less paper printing, video conferencing and interviews (Al Mamun, 2019).

Green organizational practice is important in the modern business area as the environment of the planet is shifting and becoming unsafe for human survival. We face various forms of natural disasters every year, such as hurricanes, floods, droughts, earthquake, extreme heat and ice melting, acid rains etc. Ecologists in the environment has proposed finding a sustainable equilibrium for the survival of the earth from every corner of the globe. Green HRM helps establish three foundations such as environmental sustainability, social sustainability and economic sustainability. Fortunately, certain government organizations and individuals, including environmentalists and nature lovers have come forward and paid serious attention to protect and preserve the environment. Green HRM activities is one of the crucial ways to make an organization greener and to ensure environmental protection. The practice of Green HRM benefits both the organization and community in the following ways.

Minimizes natural disasters, health diseases, and global warming due to 
pollution, Ensure the survival of humans and business organizations and ecological balance, Increases employee productivity though satisfaction and better efficiency, Lesser consumption of power-energy, water and raw materials, Attracts best talented HR and ensure to retain them for longer period, Increase organizational image and larger scale of sales and services, Lowering costs due to electronic documentations, teleworking, video conferencing, recycling of different usable products within the organization (Hossen et al, 2018).

HRM is a manifesto that helps to build green workforce inside an enterprise that can recognize and respect the green culture. Throughout the HRM process of recruiting, hiring, and training, compensating, improving and enhancing the human resources of the company. Such a green initiative will retain its green objectives. A company's human resources department is capable of playing a significant role in creating environmental culture within the company. HR processes play an important role in turning Green HR policy into practice; Thus, human capital and its management are instrumental in achieving the goals of environment managers (Ahmad, 2015).

\section{Green Job Design}

Green work design is a comprehensive job analysis that involves roles, duties and obligations related to organizational and environmental sustainability in each positions as much as possible to protect the organizational as well as environmental sustainability. In some business organizations each job description contains at least one role related to organizational and environmental sustainability. For certain business organizations, each work description includes at least one role related to organizational and environmental sustainability and also includes unique environmental obligations where applicable, job descriptions and person (job) specifications can include organization's economic, social, personal and technological requirements as far as possible (Das \& Singh, 2016).

The benefits of embracing the idea of green jobs are evident: it helps to minimize the adverse effects on the environment, eventually contributing to environmentally healthy, socially appropriate and economically viable businesses and what is called a green economy for which the participation of businesses and employees is vital. The safeguarding of inefficient use of natural resources, waste management, pollution prevention and the safeguarding of sustainable food production are notable positive results that can be anticipated by emphasizing green employment (Jayaweera et al, 2012).

\section{Green Recruitment and Selection}

Green recruitment and Selection is the process of attracting and hiring candidates with knowledge, skills, attitudes and behaviors that conform to an organization's environmental management systems. A major challenge is the race of attracting creative talented and innovative employees, increasing recruitment 
potential and hiring high-quality staff. Therefore, companies are required to learn and plan the greenways of recruiting and employing skilled workers in an attempt to ensure environmental protection at the workplace. Recruitment and selection processes will also understand the company's long-term criteria to align corporate environmental culture organizations with green recruitment and selection processes in this effort.

Basically, job description would take cognizance of health and safety duties and other associated roles affecting the environment. In fact, green targets for companies should be customized to gage the future viability of prospective applicants being recruited. Similarly, until the process of recruitment is completed, the chosen candidates have been granted a detailed green induction programme, which includes information on environmental protection and their contributions to green goals (Mashala, 2018).

To carry out the paper-free recruitment process by digital methods such as online application form, online interviews or telephone interviews are performed to minimize paper waste, fuel consumption and travel interviews. These activities reduce the rate of environmental degradation. Recruitment strategies may help to enhance environmental sustainability by ensuring that environmental culture and values are well aware of the environmental management policies of the company. In choosing job openings in certain business organizations, applicants who have experience of protecting and maintaining natural resources are chosen to support ecosystems. Environment-related questions are asked by that business organization when interviewing candidates for selection. Here, are some of the successful green hiring practices that any company should follow in order to pick environmentally sustainable people in addition to the mail selection requirements for the particular roles and obligations of the business organization concerned (Das \& Singh, 2016).

The most daunting problem faced by HR managers is to recruit and retain highly skilled and qualified workers in a global environment. MultiNational Companies are now positioning themselves as Green HRM followers to attract highly skilled and competent staff, who also have deep experience and understanding of green practices and sustainability issues. On the other hand, work candidates often train themselves in compliance with international green culture requirements and aim to acquire the skills needed as green workers. Workers also choose certain organizations that are concerned with environmentally and socially responsible.

The organization's environmental performance is influenced by green employee recruitment and the green recruitment process of recruiting. The organization's human resources must first be green of order to demonstrate good environmental efficiency (Dubey \& Gupta, 2018). 


\section{Green Training and Development}

Training and development systems built at all levels for workers will discuss the social and environmental aspects. The induction preparation for new joiners will include a green orientation programme that helps the employee to recognize the company's sustainability policies and activities and also comply with the company's green goals. Such a training programme will educate staff about the company's sustainability initiatives such as reducing greenhouse gas emissions etc (Mehta \& Chugan, 2015).

Training programme will educate workers about the company's green initiatives, such as reducing greenhouse gas emissions etc. Providing the organizational leaders with environmental training to develop the necessary technical and management skills for maintaining, preserving natural resources and fostering sustainability in the environment. It is also essential to build environmental awareness among all employees by organizationally conducting seminars and workshops to achieve organizational sustainability. It is very difficult to achieve environmental related awareness, training and growth, materializing the business organization's planned environmental efficiency. Therefore, it appears that some business organizations have recognized the value of green education, training and growth in their organization for both organizational and environmental sustainability (Das \& Singh, 2016).
Training and development is a process that focuses on skills, expertise and attitudes of workers, avoiding the degradation of information, skills and attitudes relevant to the environment. Green training and growth teach staff about the importance of environmental sustainability educating them in energy-conserving working practices, waste reduction, diffuse knowledge of the environment within the company and provide resources to involve workers in addressing environmental problems. Green training and development programmes make workers aware of the various aspects and importance of environmental management. It help them adopt different conservation methods, inside an organization like waste management. Furthermore, it enhances an employee's ability to deal with different environmental concerns (Ahmad, 2015).

\section{Green Performance and Reward Management}

Employee environmental performance in an enterprise is very difficult task. A programme of performance assessment to support the Green HR activities needed to establish environmental performance standards. Therefore, the activities and duties of job description in the company organization may be implemented in order to achieve the green goal objective.

Measuring green work efficiency for workers is one of the main roles of Green HRM. Appraisal of employee's green performance must be performed separately as part of the company's monetary-based and non- 
monetary based compensation performance evaluation programme can be used for corporate sustainability accomplishments within the business organization. Monetary benefits for environmental sustainability achievements may be distributed in salaries, bonuses and cash incentives, while non-monetary rewards can include special leave, requirements for staff and family members. Organizational sustainability of organizations is highly dependent on the organization's green reward management practices. Providing opportunities to motivate workers when the company is active in recycling and waste reduction, promoting flexible scheduling and telecommuting and minimizing long distance business travel can also be viewed as green reward management activities in the enterprise (Das \& Singh, 2016).

Green Compensation and reward is another potentially powerful tool for supporting environmental management activities. This may help to make effort for the attainment of environmental goals. Compensation and reward are the major elements of HRM process, this element is the most important for maintaining employee interest to that of the organization. The reward polices are focused on attracting, retaining and motivating the employee which lead to the achievement of organizational goal and improve the organizational commitment. Taylor et al., (1992) has done study in which he takes 16 companies from 5 different countries and examined that the companies offer green rewards to their employees for their performance were more inclined to follow the green practices. Similarly study by Forman and Jorgensen (2001) identified that the employee commitment were increased toward the environment management program when they were offered compensation to take environmental responsibilities. Dow chemical is a very good example of reward and compensation; employees were motivated and given rewards when they came up with innovative waste reduction idea (Bangwal \& Tiwari, 2015).

\section{METHODS}

This study has followed quantitative research approach and descriptive design . Survey method has used for collecting data and it was consisted with close ended questions and 5 point likert scale format. To conduct this research primary sources of data are used. A structured questionnaire has been developed based on the literature study and experts' opinions.

The Analysis has done through the SPSS package. The statistical techniques for data analysis was included descriptive statistics (mean, mode, median and standard deviation), bivariate method, correlation analysis and reliability. In addition to that, hypotheses of the study has been measured through Pearson's Correlation technique and the Researcher used SPSS for analyze, statistical concepts such as correlation, reliability and descriptive statistics.

This study has applied survey method to examine the relationship between 
variables tested in the study. This study has four independent variables as Green Job Design (X1), Green Recruitment \& Selection (X2), Green Training \& Development (X3) and Green Performance \& Reward Management (X4) while the dependent variable was Environmental Sustainability (Y).

After a population study it was identified that out of hundreds of employees there was 40 managerial level employees in fourteen branches of BOC who represent the positions of senior managers, managers, assistant managers, executive officers and junior executive officers. Therefore, the total population has been taken as the sample for this study. Accordingly, sample size was 40 for this study.

\subsection{Research Model}

The research model was based on the model created and tested by Oyewale (2019).

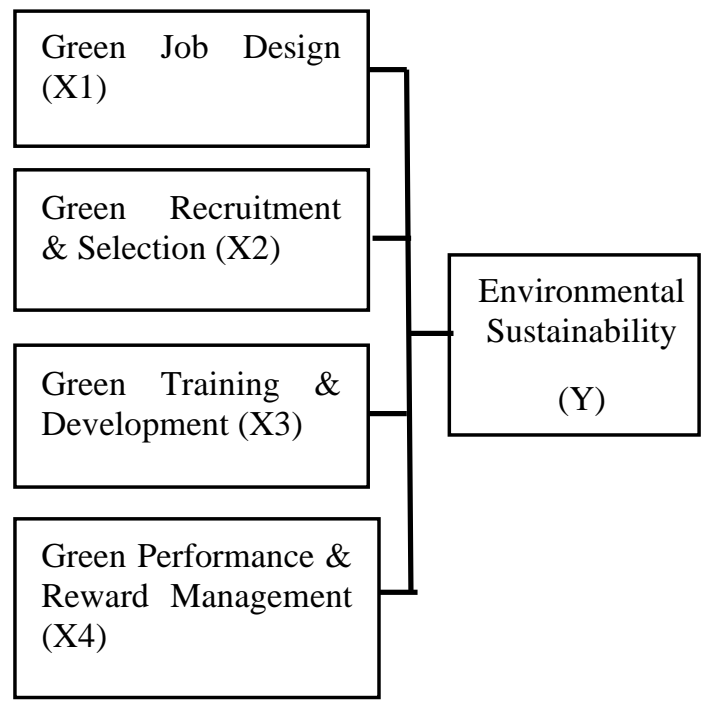

Figure 1: Conceptual framework
According to the Figure 1 Green Job Design, Green Recruitment \& Selection, Green Training and Development and Green Performance \& Reward Management are independent variables. As well as dependent variable is Environmental Sustainability. This study is going to check this combination in the organizational context.

To achieve the study objectives, the following main hypotheses was formulated:

H1: There is a significant positive relationship between Green Job Design and Environmental Sustainability.

$\mathrm{H} 2$ : There is a significant positive relationship between Green Recruitment \& Selection and Environmental Sustainability.

H3: There is a significant positive relationship between Green Training \& Development and Environmental Sustainability.

H4: There is a significant positive relationship between Green Performance \& Reward Management and Environmental Sustainability.

\section{RESULTS}

All variables were measured with questions adapted from existing scales. All items were measured on a five-point Likert-type scale where $1=$ strongly disagree and $5=$ strongly agree.

Questionnaires were analyzed responses given by responders to every question which represent both dependent and independent variables. Already tested questioner (Oyewale, 
(2019) was used to for this study. Questionnaire consists of set of wellformulated questions to problem and obtained responses from respondents. (Descriptive statistics, reliability and correlation test were used to test the relationship and hypotheses.

\subsection{Descriptive statistics}

According to Sekaran (2006) descriptive statistics such as maximum, minimum, means, standard deviations, and variance were obtained for the interval-scaled independent and dependent variables. Dependent Variable of this study is Environmental Sustainability.

Table 1: Descriptive statistics

\begin{tabular}{|c|c|c|c|c|c|}
\hline & $\mathbf{n}$ & 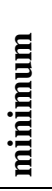 & 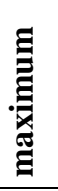 & $\underset{\Xi}{\stackrel{\Xi}{\Xi}}$ & 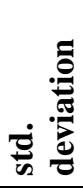 \\
\hline \begin{tabular}{|l|} 
Environmental \\
Sustainability \\
\end{tabular} & 36 & 17 & 20 & 18.64 & .723 \\
\hline $\begin{array}{|ll|}\text { Green } & \text { Job } \\
\text { Design } & \\
\end{array}$ & 36 & 17 & 20 & 19.17 & .941 \\
\hline $\begin{array}{l}\text { Green } \\
\text { Recruitment \& } \\
\text { Selection }\end{array}$ & 36 & 16 & 20 & 17.28 & 1.06 \\
\hline $\begin{array}{l}\text { Green Training } \\
\& \\
\text { Development } \\
\end{array}$ & 36 & 14 & 18 & 15.53 & 1.29 \\
\hline $\begin{array}{l}\text { Green Reward } \\
\text { \& Performance } \\
\text { Management } \\
\end{array}$ & 36 & 8 & 13 & 10.55 & 1.46 \\
\hline $\begin{array}{|lll|}\begin{array}{l}\text { valid } \\
\text { wise) }\end{array} & \text { (list } \\
\end{array}$ & 36 & & & & \\
\hline
\end{tabular}

Source: Analysed data, 2020

Table 1 is indicated that the mean $\&$ standard deviation of the variables. Green Job Design, Green
Recruitment \& Selection, Green Training \& Development and Green Performance \& Reward management has 19. 17, 17.28, $15.53 \& 10.55$ mean value and $0.72,0.94,1.06,1.29$ \& $\quad 1.46 \quad$ standard deviation respectively.

\subsection{Reliability of the Measures}

Table 2: Reliability Statistics

\begin{tabular}{|c|c|c|}
\hline \multicolumn{3}{|l|}{ Reliability statistics } \\
\hline & $\begin{array}{l}\text { Cronbach's } \\
\text { alpha }\end{array}$ & $\begin{array}{l}\text { No of } \\
\text { items }\end{array}$ \\
\hline Green Job Design & .841 & 4 \\
\hline $\begin{array}{l}\text { Green } \\
\text { Recruitment\& } \\
\text { Selection }\end{array}$ & .800 & 4 \\
\hline $\begin{array}{l}\text { Green Training \& } \\
\text { Development }\end{array}$ & .781 & 4 \\
\hline $\begin{array}{l}\text { Green Performance } \\
\text { \& Reward } \\
\text { Management }\end{array}$ & .735 & 4 \\
\hline
\end{tabular}

Source: Analysed data, 2020

According to the table 2 Cronbach's Alpha value for Green Job Design is 0.841. For an instrument to be considered a reliable data collection tool this value should be greater than 0.7 . This value is greater than above the required 0.7 which indicates that the instrument and data collected for the purpose of this research has a high reliability. So, in this context, the questions used to measure the Green Job Design is highly reliable one. Likewise Green Recruitment \& Selection, Green Training \& Development and Green Performance \& Reward management also have a greater Cronbach's Alpha value than 0.7. Therefore, it can be concluded 
that the questions used to measure the Green Recruitment \& Selection, Green Training \& Development and Green Performance \& Reward Management are also highly reliable.

\subsection{Correlation Analysis}

Table 3: Correlation between dependent and independent variables

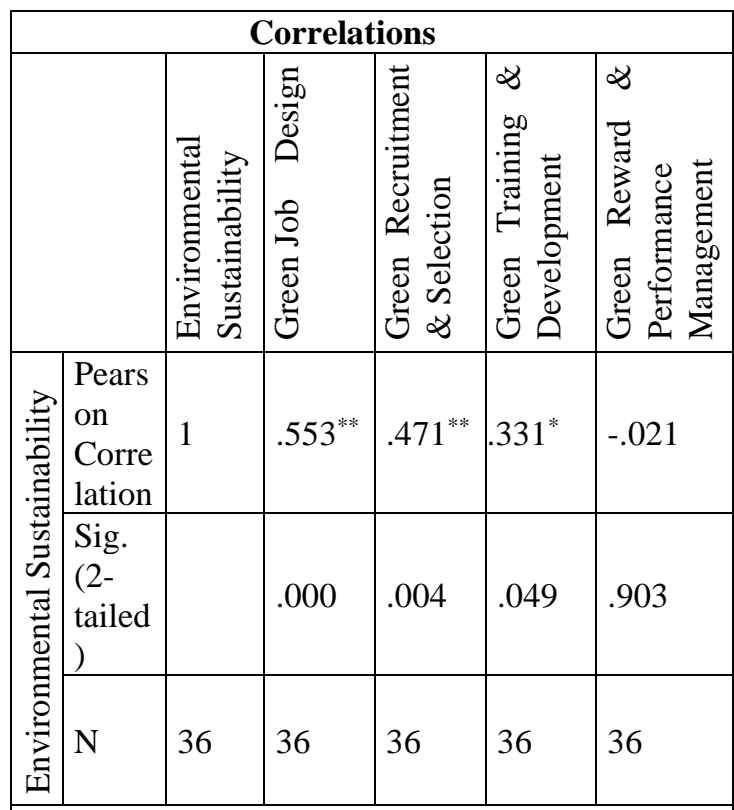

*. Correlation is significant at the 0.05 level (2tailed).

Source: Analysed data, 2020

Correlation analysis is a statistical technique which can use to show the relationship between variables. Most common methods that can use for measure the correlation are Perarson \& Product-moment correlation.This study has mainly used Pesrson correlation for analyze the data and hypotheses.

The Pearson correlation value for Green Job Design and Environmnental Sustainability is 0.553 and it has a moderate positive relationship. Hence the significance value is less than $0.05 \mathrm{H} 1$ is accepted.

Green Recruitment and selection has a moderate positive relationship with Envirnomental Sustainability and $\mathrm{H} 2$ can be accepted because of the significance value is less than the alpha value.

The Peasorn correlation value for Green Training \& Development is 0.331. It is a low positive relationship.the alpha value is less than the significance value.So, H3 is accepted.

According to the correlation table 3 the correlation cofficent is -0.21 between Green Performance \& Reward management. It has indicated that there is a negative relationship between the independent and the dependent variable.Therefore, it can be statistically indicated that there isn't a significant as well as positive correlation between these two variables. Then, the researcher can't accept $\mathrm{H} 4$.

\section{DISCUSSION}

This section represent the basic findings of GHRM and Environmental Sustainability. The basic findings demonstrate the basic assumptions proposed along with the interpretation of GHRM and theoretical frame work. Considering the analytical approach, finding based on the current literature was found. The literature indicates that sceintists have invented and branded the idea of GHRM as a panacea for environmnetal management in contemporary organizations after the development of Human Resource 
Management to focus on Environmnetal Sustainability (Jackson \& Seo, 2010; Renwick et al, 2013).

There is a agreement among scholars in this entire content that GHRM compatibility with conventional HRM practices enhances organizational

enviromental management (Jackson et al, 2014) and essentially in the apoption of broad organizational practices (Schuler \& Jackson, 2014). As such, the contribution of GHRM dimensions to enhancing the application of green management principles by employees within the company is given importance (Cherian \& Jacob, 2012; Opatha \& Arulrajah, 2014).

When considering the literture, some schorlars have identified positive relationship between Green HRM functions and Environmental Sutsiannbility.Green HRM fuctions such as Green Job Design, Green Recruitment \& Selection, Green Training \& Development and Green Performnace \& Reward Management have a positive influence on Environmnetal Sustainability (Jabbour, 2011). In terms of green recruitment \& selection, the results indicate that recruitment strategies can promote environmental management practices in organizations by ensuring that new hires recognize the environmental culture of organizations and share their environmental values(Jackson et al, 2011).

Similarly, organizations that opt to use preserve their image as green employer (Jackson et al, 2011), They recruit new talents, high quality workers with an environmental beliefs (Ahmad, 2015). Green Training \& Development is another GHRM function which has the direct impact on Environmnetal Sustainability. It is the most important HRM factors for the achievement of the environmental performance (Haddock-Miller et at, 2015). Renwick et al, (2013) suggests that well-trained and environmentally conscious front-line employees conserve the environmnet as they are ideally positioned to identify and reduce waste by their places.

Green rewards and compensations, on the other hand, places the company and an excellent environmental performance. Organizations that reward the constructive green actions of their workers to increase their efficiency and royalty and thereby encourage them to change their environment positively.

But this study has explored that there is a positive relationship with the independent variables;Green Job Design, Green Recruitment \& Selection, Green Training \& Development and a negative relationship with Green Performance \& Reward Management on Environmental Sustainability. Although Bank of Ceylon gives their concern in job design, rectuitment \& selection and training \& development they don't reward their employees to motivate the employees more.

Organizations will enable workers to think about solutions that can help to reduce carbon emissions through 
participation and involvement in green organizational projects and by aligning their motivation, priorities and skills with green management practices, contribute to better green management in the company (Mashala, 2018).

\section{CONCLUSION}

The study assessed the relationship between Green Human Resource functions such as Green Job Design, Green Recruitment and selection, Green Training and Development and Green Performance and Reward Management \& Environmental Sustainability. The organizational problem is to ascertain the ideal Green HRM system which could be utilized to increase Environmental Sustainability and at the same time to achieve Organizational Objectives.

The first objectives of this study was to identify the relationship between Green Job Design and Environmental Sustainability in BOC branches in Matale district. According to the analyzed data it was showed that there is a positive relationship between these two variables which means when we increase Green Job Design activities it helps to increase the Environmental Sustainability. It is clear that Bank of Ceylon has a Green Job Design initiatives or criteria when forming a job according to the analyzed data. Bank of Ceylon uses a comprehensive job analysis that involves roles, duties and obligations related to organizational and environmental sustainability in each positions as much as possible to protect the organizational as well as environmental sustainability.
The second objective of this study was to identify the relationship between Green Recruitment and Selection and Environmental Sustainability. According to the study there is a positive relationship between these two variables. Therefore, Bank of Ceylon uses the process of attracting and hiring candidates with knowledge, skills, attitudes and behaviours that conform to an organization's environmental management systems.

The third objective of this study was to identify the relationship between Green Training and Development and Environmental Sustainability. When considering the analyzed data it is clear that there is a positive relationship between this dependent and independent variable. Which has proved that Bank of Ceylon was used any kind of training and development practices according to the green aspects.

The last objective of this research was to identify the relationship between Green Performance and Reward Management \& Environmental Sustainability. But there is a negative relationship between these two variables according to the data outputs. So it is obviously proved that Bank of Ceylon is not reward much other employees to achieve Environmental Sustainability.

Accordingly this study was done to assess the practical situation of Green HR in a Bank of Ceylon in Sri Lanka. This study supports the systematic literature of Green HRM and environment protection that is little in developing countries like Sri Lanka. 
Also it provides a clear understanding on how Green HRM practices associate with each other. In the near future, GHRM as an initiative has the potential to be worked upon as one of the best practices for sustainable growth of businesses.

Some of the limitations of the study can also be identified which will be helpful in further researchers. This research has been limited to fourteen Bank of Ceylon branches in one district. The sample has taken from only in Matale district and it was difficult to collect data from other branch. And also only 36 employees were responded out of 40 managerial employees. At the same time, though this quantitative analysis, the findings may not be enough to generalize to the entire Bank of Ceylon branches. It will be more reliable to select a sample which contains more elements in different public banks. So, this was a limitation of the study. Another limitation of the study is the data collected method. The data has been collected only through the questionnaires. It might not be sufficient and also respondents may not have enough time to put answers and read questionnaires because staffs of the bank was very busy in whole day. It also can be identified as a limitation of the study. Another limitation of this study was there were only four independent variables were assessed in here because the limitation of the time and to limit the scope of the subject. The other limitation was lack of literature in the Sri Lankan context regarding this matter. The researcher found it difficult to gather data with regard in the Sri Lankan business context.
There were some researches on Green banking in Sri Lanka conducted by many scholars. But even still it is an evolving subject or new subject in Sri Lanka. Hence, it was so difficult to find related research on this subject in banking industry in Sri Lanka.

This study further recommends a proper reward system for green employees, appreciates green employees when they do a green activity, providing regular feedbacks to achieve environmental goals or improve their environmental performance, conducting online training programmes, Appreciating green activities by giving additional points in interviews, creating environmental clubs to organize environmental programmes and giving opportunity to all staff members to participate awareness programmes about environmental degradation to increase the awareness and practice on Green HRM in the public banking sector.

Green HRM has a significant contribution to sustainability in the environment. The definition places priority on both companies and workers in working together to protect the environment and enhance the efficiency of companies. However, Although its activities in Sri Lanka's public banks are fresh, Green HR initiatives will concentrate on reducing and eliminating environmnetal waste, rehabilitating HR goods, tooling procedures to achieve greater productivity and lower costs. 
The bottom line is creating a green culture where all workers engage in organizational green management and sustinability efforts. In addition, green issues have consequnces for the operations of the HR department.Thus, green issues and policies should be incorporated into the normal, day-to-day HRM activities and decisions. This hopes to stimulate understanding of the concept of Green HRM and it's practices solving environmnetal issues in Bank of Ceylon.

\section{REFERENCES}

Ahmad,S., 2015. Green Human Resoucre Management : Policies and Practices. Cogent Business \& Management.

Al Mamun,M.A., 2019. An Analysis of Employee Awareness on Green Human Resource Management. Human Resource Management Research, pp. 1421.

Arulrajah.A.A.,Opatha,H.H.D.N.P.,\& Nawaratne,N.N.J., 2016. Emplyee Green Performance of Job: A Sytematic Attempt towards Measurement. Sri Lankan Journal of Human Resource Managemet, pp. vol.6,No.1.

Bangal.D \& Tiwari.P, 2015. A way to greening the environment. IOSR Journal of Business and Management, pp. VOl.17,Issue.12.

Cherian,J.P.,\& Jacob,J., 2012. A Study of Green HR Practices and its effective implementation in the organization: A review. International Journal of Business and Management.

Das,S.C,\& Singh,R.K., 2016. Green HRM and Organizational Sustainability: An Empirical Review. Kegees Journal of Social Science, pp. 227-236.

DeFreitas..S,,W.R.,Jabbour,C.J.C.,M angili,L.L.,Filho,W.L.,\& de Olivia,J.H.C., 2012. Bulding Sustainable values in Organizations with the Support of Human resource Management: Evidence from One firm considered as the "Best Place to Work" in Brazil. Journal of Human Values, pp. 147-159.

Dubey,S.,\& Gupta,B., 2018. Linking Green HRM Practices with Organizational Practices for Organizational and Environmetal Sustainability. International Journal of Engineering and Management Research, pp. 149-153.

Haddock-Miller,J.,Sanyal,C.,\&

Muller- Camen,M.,, 2016. Green Human Resource Management : a comparative qulalitative case study of a United States multinational corporation. The International Jounal of Human Resource Management, pp. 192-211. 
Hossen.M.Md.,Ashadullah,Md.,\&

Islam,R., 2018. Green Human

Resource Management

Practices in Bangladesh: A

Study on the Banking Sector.

The Jahangirnagar Journal of

Business Studies, pp.

Vol,7,No.1.

Islam,M.M.,Islam,J.Md,Pervez,A.K.

M.K.,\& Nabi,N.N.J., 2019. Green HRM and Green Business: A Proposed model for Organizational

Sustainability. Environmental Management and Sustainable Developmemt, pp. Vol.8,No.3.

Jabbour,J.C.,, 2011. How Green are HRM practices,organizational culture,learning and team work? A Brazilian study. Industrial and Commercial Training, pp. 98-105.

Jackling,B., 2000. A Future for Sustainability. Water,Air \& Soil Pollution, pp. 467-476.

Jackson,S.E.,\& Seo,J., 2010. The greening of strategic HRM scholarship. Organization Management Journal, pp. 278290.

Jackson,S.E.,Renwick,D.W.,Jabbour, C.J.\& Muller-Camen,M., 2011. State of the Art and future directions for Green Human Resource Management: Introduction to the special issue. German Journal of Human Resource Management, pp. 99-116.
Jayaweera,M.,Manatunge,J.,\&

Witharana,A., 2012. From

Greener to Greener: Good practices and Training Need for Green Jobs in Sri Lanka, Sri Lanka: Employee's federation of Ceylon.

Jessy, N. S., 2017. Linked in. [Online]

Available at:

http://www.linkedin.com

John,M., 2011. Environmental Sustinablity: A Definition for Environmental Professionals. Journal of Environmental Sustainability, p. Vol.1.

Oyewale,O, 2019. Green Human Resource Management Practices (GHRM) and Its Effect on Sustainable Competitive Edge in the Nigerian Manufacturing Industry: A Study of Dangote Nigeria Plc.

Kusumanchi, S., 2019. Quora. [Online] Available at: http://www.quora.com

Likhitkar,M.P., \& Verman,P., 2016. Impact of Green HRM practices on Organizational Sustainability and employee retention.

Mashala,Y.L,, 2018. Green Human Resource Management and Environment Sustainability in Tanzania: A Review and Research agenda. International Journal of Academic 
Multidisciplinary Research, pp. 60-68.

Masood, R., 2018. Green HRM: A Need for 21st Century. JETIR, pp. Vol.5,Issue 6.

Mehta,K.,\& Chugan,P.K., 2015. Green HRM in Pursuit of Environmentally Sustainable Business. Universal Journal of Industrial and Business Management, pp. 74-81.

Milliman.J.,\& Clair,J., 1996. Best environmental HRM practices in the US. Greening people: Human Resource and Environmental Management, pp. 49-47.

Noronha,L.D.M.,Manjush,H.,\& Monteiro,M., 2016. A study on the Green Human Resource Management at Gateway Hotel, Mangalore, s.1.: s.n.

Opatha,H,.\& Arulrajah,A,A,, 2014. Green Human Resource Management: Simplified general reflections. International Business Research, p. 101.

Opatha,H.H.D.N.P.,, 2013. Green Human Resource Management: A Simplified Introduction. Proceedings of the HR Dialogue, pp. Vol.1,No.1.

Renwick,D.W.S.,Redman,T.,\&

Maguire,S., 2013. Green Human Resource Management: A review and research agenda.
International Journal of Managemet Reviews, pp. 1-14.

Schuler,R.\& Jackson,S., 2014. Human Resource Management and Organizational Effectiveness: Yesterday and Today. Journal of International effectiveness, pp. 35-55.

Sekaran,U., 2006. Research Methods for Business:A Skill Building Appraoch. John Willy \& Sons.

Sharma,K., 2016. Conceptualization of Green HRM and Green HRM practices: Commitment to Environmnrtal Sustainability.

Shaumya,K.\& Arulrajah,A.A., 2016. Measuring Green Banking Practices: Evidence from Sri Lanka. 13th International Conference on Business Management.

Sri Lanka Environment, 2018. Knoema. [Online] Available at: https://knoema.com/atlas/SriLanka/Co2-emissions

Uddin,M.M.,\& Islam,R., 2015. Green HRM: Goal Attainment through Environmental Sustainability. The Journal of Nepalese Business Studies.

youmatter, 2018. [Online] Available at: http://www.youmatter.world.co $\underline{\mathrm{m}}$ 